REVIEW

\title{
Postnatal steroid treatment and brain development
}

\section{O Baud}

Arch Dis Child Fetal Neonatal Ed 2004;89:F96-F100. doi: 10.1136/adc.2003.028696

This review examines the risk/benefit ratio of postnatal steroid treatment in preterm infants and correlates epidemiological data with experimental evidence on the effect of glucocorticosteroids on brain development.

s n 1972, Liggins and Howie ${ }^{1}$ reported the first study showing the value of prenatal steroids given to mothers at risk of preterm delivery. Subsequently, many randomised trials confirmed that prenatal steroids reduce mortality and the incidence of respiratory distress syndrome and intraventricular haemorrhage in premature infants. $^{2-5}$ These findings led the National Institutes of Health to recommend routine prenatal administration of steroids between 24 and 34 weeks gestation when there is a risk of preterm delivery. ${ }^{3}$

On the other hand, the first study of postnatal steroid treatment in preterm infants was published as early as 1956 and evaluated the effects on respiratory distress syndrome in neonates born to diabetic mothers. ${ }^{6}$ The first controlled study, reported by Baden et al in 1972, compared hydrocortisone with a placebo given at admission and 12 hours later in 44 premature infants with respiratory distress syndrome. ${ }^{7}$ No significant benefits were found in the steroid treated infants. In the 1980s and early 1990s, several controlled studies indicated that postnatal steroid treatment was associated with shorter times on oxygen and mechanical ventilation, and as a result this treatment gained widespread acceptance. Most of these controlled studies used intravenous dexamethasone and measured the incidence and severity of chronic lung disease in low birthweight infants as the primary outcome variables. ${ }^{8-11}$ Controversy about the extensive use of postnatal steroid treatment has arisen recently in response to reports of adverse effects, mainly on the central nervous system. This review examines the risk/benefit ratio of postnatal steroid treatment in preterm infants and correlates epidemiological data with experimental evidence on the impact of steroids on brain development.

Correspondence to: Dr Baud, Service de Néonatologie et Laboratoire de Neurobiologie du Développement, INSERM E9935, Hôpital' Robert Debré, 48 bd sérurier, 75019 Paris, France; olivier.baud@ rdb.ap-hop-paris.fr

Accepted 8 April 2003 .................... vous system and lungs. In a very large prospective cohort of infants born before 32 weeks gestation, $27 \%$ of infants had intraventricular haemorrhage of any grade and $7 \%$ of the most severe grades, $5 \%$ had periventricular leucomalacia (PVL), and nearly $21 \%$ had white matter disease, which led to cerebral palsy in $9.3 \%$ of the cohort at 2 years of age. ${ }^{12}$ Chronic lung disease, the most common form of respiratory disease in very immature infants, is present in over $70 \%$ of 28 day old infants born before 28 completed weeks gestation. In two studies conducted in North America in the 1990s, $23-26 \%$ of very low birthweight infants had chronic lung disease at term. ${ }^{13}{ }^{14}$ Bronchopulmonary dysplasia is related chiefly to inflammatory disease of the premature lungs. As suggested by Jobe and Ikegami, ${ }^{15}$ chronic lung disease develops in response to injury from mechanical ventilation and supplemental oxygen. Early lung inflammation in infants with bronchopulmonary dysplasia has been ascribed to these factors. In addition, cytokine release into the amniotic fluid leads to an inflammatory response in the fetus, the fetal inflammatory response syndrome, which predominantly involves the lungs and brain, increasing the risk of white matter damage. After birth, steroids are mainly used to prevent inflammation caused by intrauterine infection. Postnatal steroid treatment was first recommended to prevent or treat bronchopulmonary dysplasia and used to treat haemodynamic failure, to good effect. Currently, three regimens are used: (a) early treatment, during the first 96 hours after birth, followed by rapid discontinuation; (b) moderately early treatment, between postnatal days 7 and 14, followed by dose tapering; (c) delayed treatment, given after 3 weeks of age, usually in patients receiving assisted ventilation.

From Cochrane meta-analyses, figs 1 and 2 summarise the risk/benefit ratio of postnatal steroid treatment according to the treatment regimen. ${ }^{16-18}$ With all regimens, steroid treatment consistently reduced the need for assisted ventilation at 28 days of postnatal age or at term. In contrast, neither of the two early regimens decreased the need for oxygen at term, and no studies found a reduction in neonatal mortality. The respiratory benefits documented in these studies should be weighed against the well known or possible adverse effects. Hyperglycaemia and hypertension are treatable complications of steroid treatment. However, intestinal tract complications including gastrointestinal bleeding and perforation can cause death. ${ }^{19}$ The main adverse effect with the early regimen is an increased risk of cerebral palsy, which is sometimes also observed with the 


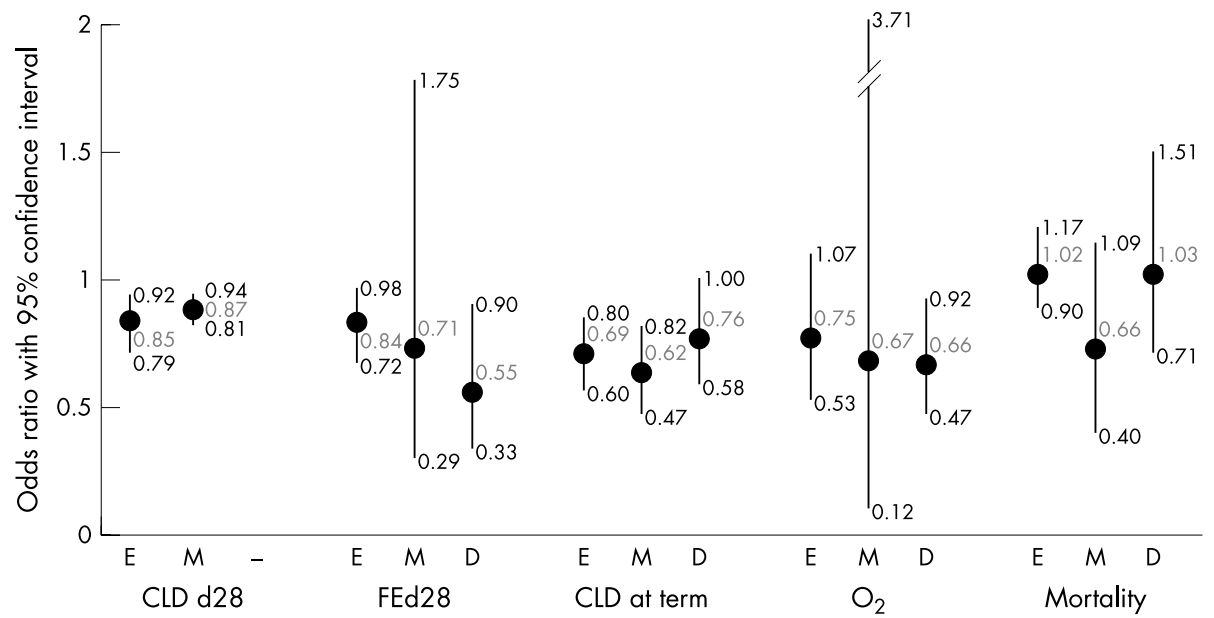

Figure 1 Main benefits of postnatal steroid treatment in preterm infants according to the regimen used. ${ }^{16-18} \mathrm{E}$, Early regimen $(<96 \mathrm{~h}$ of life); $\mathrm{M}$, moderately early regimen (7-14 days of life); $D$, delayed regimen ( $>3$ weeks of life); CLD, chronic lung disease; FEd28, failure to extubate at day 28 ; $\mathrm{O}_{2}$, oxygen at home.

delayed regimen. ${ }^{20-25}$ In controlled and open studies, brain lesions and cerebral palsy were more common after early dexamethasone treatment. Although the most recent studies found no additional physical or neurodevelopmental impairments at 3 years of age in patients given early or moderately early dexamethasone treatment, ${ }^{26}{ }^{27}$ the small sample sizes and suboptimal study design invite caution when interpreting these results. The only behavioural study of spontaneous motility in neonates found that dexamethasone treatment was associated with reduced motility and changes in the speed and amplitude of general movements, and that these effects correlated with the severity of brain lesions and subsequent occurrence of cerebral palsy. ${ }^{28}$

\section{BRAIN MAGNETIC RESONANCE IMAGING, PREMATURITY, AND POSTNATAL STEROIDS}

The incidences of both respiratory distress syndrome and intraventricular haemorrhage have decreased substantially, leaving prevention of white matter damage among the greatest challenges faced by perinatologists. The cystic form of PVL is the leading cause of cerebral palsy in children surviving preterm birth, with a rate of $5-15 \%$ among infants born before 32 weeks gestation. ${ }^{29}$ In extremely preterm infants imaged at term, PVL was associated with decreases in cortical grey matter volume, cortical surface area, and cerebral cortex complexity. ${ }^{30}$ These findings are of special interest because they provide the first incontrovertible evidence that white matter damage can interfere with grey matter development and probably with neurogenesis. Similarly, Murphy et $a l^{31}$ used three dimensional magnetic resonance imaging to quantify at term the influence of postnatal systemic dexamethasone treatment on brain growth and development in infants without evidence of white matter injury or intraventricular haemorrhage. Together with an additional report, ${ }^{32}$ these data suggest that steroid induced impairment of brain growth may primarily affect the cortical grey matter and may spare the white matter and basal ganglia. In keeping with this finding, repeated prenatal steroid treatment was associated with a decrease in brain surface area and in the whole cortex convolution index, which is used to measure cortical surface complexity. ${ }^{33}$ Similarly, in 1968, Howard ${ }^{34}$ reported that corticosterone given to mice between 2 and 14 days of age interfered with synthesis of DNA, RNA, and protein in the brain and produced irreversible reductions in brain size, weight, and cell numbers that persisted throughout most of

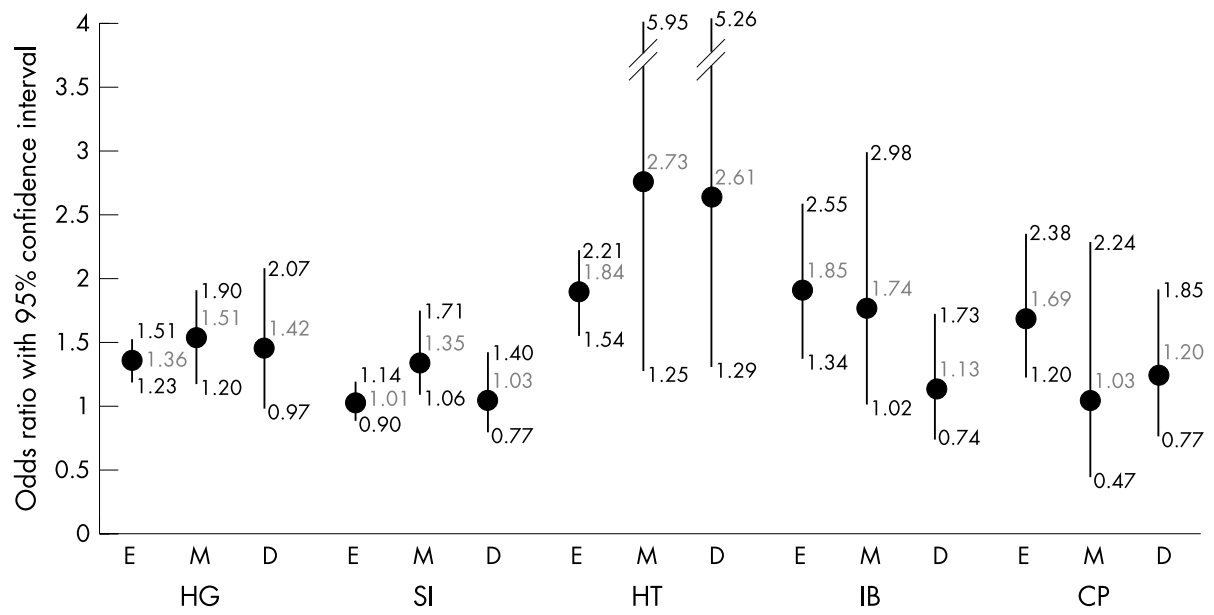

Figure 2 Main adverse effects of postnatal steroid treatment in preterm infants according to the regimen used. ${ }^{16-18} \mathrm{E}$, Early regimen (<96 $\mathrm{h}$ of life); $M$, moderately early regimen (7-14 days of life); D, delayed regimen ( $>3$ weeks of life); HG, hyperglycaemia; SI, secondary infection; HT, arterial hypertension; IB, intestinal bleeding; CP, cerebral palsy. 
the life span. Although neurones in most areas of the human brain stop dividing by the third trimester, neurones in the hippocampal dentate gyrus continue to divide long after term and therefore remain vulnerable to adverse influences. The mechanisms by which steroids reduce brain growth remain unclear but probably include inhibition of growth factors and facilitation of apoptosis. ${ }^{35}$

\section{EXPERIMENTAL STUDIES}

There is growing evidence from experimental animal studies that steroids can adversely affect the growth and development of the immature brain. In general, the sequence of brain growth events is very similar in laboratory animals and humans, although the timing differs widely. Moreover, rodent and human neurones share the same composition and electrical properties. In humans, except in the cerebellum and dentate gyrus, neuronal division is completed before the 22nd week of gestation, and subsequent cell division in the brain involves only the glia, most notably the oligodendroglial cells. A 7 day old rat is roughly equivalent to a full term human infant in terms of brain growth, periventricular germinal matrix, neurochemistry, and synapse formation. ${ }^{36} \mathrm{~A}$ 1 day old rat corresponds to a human fetus with a gestational age of about 22-24 weeks.

\section{Postnatal steroids and pathogenesis of PVL}

PVL, the major pathological correlate of cerebral palsy in premature infants, appears to result from a combination of several events:

- Inflammation caused by fetal or neonatal infection. The risk factors for PVL point to a major role for cytokines in the development of white matter damage. ${ }^{37} 38$ Thus, cytokine production was shown to correlate with premature rupture of the membranes and chorioamnionitis, two of the main risk factors of PVL. ${ }^{39}$ Moreover, in a large epidemiological study, Nelson et al ${ }^{40}$ reported a striking association between circulating cytokine increase in the perinatal period and cerebral palsy at full term.

- Hypoxia-ischaemia during the perinatal period. The chronic myelination disturbance resulting from PVL suggests a pathogenic role for oligodendrocytes. Moreover, maturation dependent vulnerability of oligodendrocytes to hypoxia-ischaemia and subsequent oxidative stress has been shown. ${ }^{41} 42$

- Growth factor deficiencies, which vary with the developmental stage of the fetal brain. The role for this factor supports the concept of a continuum from early diffuse to late focal white matter damage. ${ }^{41}$

- Potential iatrogenic insults during neonatal management. ${ }^{23}$

Of these factors involved in development of white matter damage, there is strong evidence that steroids affect brain responses to hypoxia-ischaemia, although the results are conflicting. Deleterious effects of steroids include:

- decreased survival after prenatal dexamethasone treatment among 1 day old rats breathing $5 \% \mathrm{O}_{2}{ }^{43}$

- exacerbation of neuronal and astroglial injury induced by hypoxia or hypoglycaemia in fetal rat hippocampal cell cultures exposed to corticosterone ${ }^{44}$

- decrease in the number of surviving motor neurones after nerve transaction ${ }^{45}$

- increased ischaemic brain damage after carotid artery occlusion $^{46}$

In contrast, protective effects have been also reported:
- decrease in brain injury when dexamethasone was given before unilateral carotid occlusion in a hypoxia model in 7 day old rats ${ }^{47}$

- dexamethasone pretreatment of fetal rat cells from the basal forebrain cultured in an environment deprived of oxygen and glucose resulted in a dose dependent increase in cell damage, whereas continuous exposure to dexamethasone before, during, and after the insult was protective $^{48}$

- neuroprotective effects of betamethasone or dexamethasone after excitotoxin administration. ${ }^{49}$

At the molecular level, release of excitatory amino acids in response to hypoxia-ischaemia or inflammation leads to neuronal cell death through interaction with the NMDA glutamate receptor. Prenatal or postnatal steroid treatment alters the properties of NMDA glutamate receptors. Whereas dexamethasone treatment had no effect on NMDA affinity for MK-801 in fetuses or adults, a significant $20 \%$ decrease was noted in newborn lambs, suggesting that dexamethasone may modify NMDA receptor properties only during a specific period of brain development. ${ }^{50}$

The developing white matter has a window of sensitivity to excitotoxic damage in mice, which coincides with transient NMDA receptor expression by white matter cells..$^{51}$ Microglia modulation may also be an interesting target for PVL prevention and, in theory, the anti inflammatory effects of dexamethasone treatment should diminish the brain damage associated with fetal inflammatory response syndrome. However, no such effect has been shown with nonsteroidal anti-inflammatory drugs or steroids.

\section{Postnatal steroids and neuronal maturation}

Regarding the impact of steroids on neurogenesis, Schwab et $a^{53}$ showed that betamethasone treatment in sheep reduced the concentrations of microtubule associated proteins, which are involved in neuronal maturation during late neurogenesis. This reduction in expression of microtubule associated proteins was associated with a significant decrease in regional cerebral blood flow in the frontal cortex and caudate putamen, without detectable histological brain damage.

In addition, steroid treatment during critical periods of brain development may impair myelination and brain cell division, resulting in longer term behavioural effects. ${ }^{54}$ Single doses of dexamethasone given to rats on postnatal day 4 or 7 were associated with subsequent behavioural disturbances, reduced cerebellar weight, and impairments in spatial learning and motor coordination..$^{55}$

A single study using a murine model of tapering dexamethasone treatment in the neonatal period has been reported to date. ${ }^{56}$ Dexamethasone treated animals exposed to tapering doses of dexamethasone exhibited delays in gross neurological development on postnatal days 7 and 14 but not 20. In late adolescence (day 33), dexamethasone treated animals were less active in light and dark environments, in keeping with the increased risk for learning impairment and maladaptive responses to the environment in children with prematurity related white matter damage. Postnatal steroid treatment was also associated with a significant increase in the number of GABAergic neurones in the mouse cerebral cortex, whereas no changes occurred in the expression of other markers of neuronal differentiation (unpublished observations). These findings are consistent with another study showing complex alterations in the levels of GAD65 and GAD67 gene transcription in the hippocampus. ${ }^{57}$ In rats, repeated dexamethasone injections during the second week of life also enhanced the maturation of postnatal cholinergic neurones by increasing nerve growth factor concentrations. ${ }^{58}$ Thus, alterations in neuronal maturation may account in part 
for the adverse neurodevelopmental effects of postnatal dexamethasone treatment in premature infants.

\section{A role for sulphiting preservatives}

Even if a growing body of experimental data suggests that steroids may alter late neurogenesis and neuronal maturation, a crucial question is whether the dexamethasone molecule itself is the culprit. This question was raised when a study suggested that dexamethasone and betamethasone differed in their ability to protect against white matter damage in very premature infants treated prenatally. ${ }^{59}$ Postnatally, dexamethasone is the only steroid used to prevent chronic lung disease in most published trials, precluding comparisons across steroid preparations. Injectable preparations of dexamethasone usually contain sulphites, whereas injectable betamethasone does not. Sulphites are neurotoxic in vitro, and this effect is exacerbated by the presence of peroxynitrite produced in response to hypoxia-ischaemia or inflammation. Sulphites have excitotoxic-like properties and may play a key role potentially related to postnatal steroid neurological toxicity. Indeed, in a recent study, the combination of dexamethasone and sulphites was toxic to neuronal cultures, whereas the dexamethasone molecule itself was not. ${ }^{60}$

\section{AN ALTERNATIVE TO POSTNATAL DEXAMETHASONE}

Two other glucocorticoid molecules have been evaluated recently as alternatives to fluorinated glucocorticoids. Watterberg et $a l^{61}$ conducted a randomised, double masked, placebo controlled pilot study to test whether low dose hydrocortisone for 12 days begun within 48 hours of birth increased survival in extremely premature infants without chronic lung disease. Hydrocortisone treated infants were more likely to achieve the primary outcome criterion, namely, survival without supplemental oxygen at term. The benefit was particularly pronounced in infants born from pregnancies complicated by chorioamnionitis, the main risk factor for both chronic lung disease and PVL.

Another glucocorticoid, methylprednisolone, has been evaluated in very preterm infants at risk of chronic lung disease, in comparison with 45 consecutive historical cases of infants treated with dexamethasone. ${ }^{62}$ The methylprednisolone treated infants showed faster gain in body weight during the treatment period than the dexamethasone treated infants. Methylprednisolone was as effective as dexamethasone and had fewer side effects. However, randomised control trials are needed to further study the efficacy and safety of these two steroids.

To conclude, early use of dexamethasone should especially be avoided for postnatal steroid treatment in premature infants. Until larger randomised trials are available, treatment with physiological doses of hydrocortisone may be appropriate in patients with haemodynamic failure. As betamethasone is a largely untested drug in the newborn, it cannot be recommended, even in a short course, for ventilated infants who are unstable, except within the context of a randomised controlled trial. Inhaled steroids administered for one to four weeks were safe and improved the ability to extubate premature infants, but no clear conclusion could be derived from available controlled trials in non-ventilated infants. ${ }^{63}$ The experience acquired with dexamethasone teaches a lesson in evidence based practice. Most treatments used in neonates are still largely investigational and therefore in need of well designed studies with long term follow ups.

\section{REFERENCES}

1 Liggins GC, Howie RN. A controlled trial of antepartum glucocorticoid treatment for prevention of the respiratory distress syndrome in premature infants. Pediatrics 1972;50:515-25.

2 Crowley P, Chalmers I, Keirse MJNC. The effects of corticosteroid administration before preterm delivery: an overview of the evidence from controlled trials. Br J Obstet Gynaecol 1990;97:133.

3 Consensus Development Panel. Effect of corticosteroids for fetal maturation on perinatal outcomes. National Institutes of Health Conference Statement. Bethesda, MD: US Department of Health and Human Services, Public Health Service. National Institutes of Health 1994 Feb 28-Mar 2;12:1-24.

4 Rennie JM, Wheater M, Cole TJ. Antenatal steroid administration is associated with an improved chance of intact survival in preterm infants. Eur J Pediatr 1996;155:576-9.

5 Crowley P. Prophylactic corticosteroids for preterm birth. Cochrane Database Syst Rev 2003:(1).

6 Haddad H, Hsia D, Gellis S. Studies on respiratory rate in the newborn. Its use in the evaluation of RDS in IDM. Pediatrics 1956;17:204-12.

7 Baden M, Bauer CR, Colle $E$, et al. A controlled trial of hydrocortisone therapy in infants with respiratory distress syndrome. J Pediatr 1972;50:526-34.

8 Mammel MC, Green TP, Johnson DE, et al. Controlled trial of dexamethasone therapy in infants with bronchopulmonary dysplasia. Lancet 1983;1:1356-8.

9 Avery GB, Fletcher $A B$, Kaplan $M$, et al. Controlled trial of dexamethasone in respirator dependent infants with bronchopulmonary dysplasia. Pediatrics 1985;75:106-11.

10 Bhuta T, Ohlsson A. Systematic review and meta-analysis of early postnatal dexamethasone for prevention of chronic lung disease. Arch Dis Child Fetal Neonatal Ed 1998;79:F26-33.

11 Halliday HL. Clinical trials of postnatal corticosteroids: inhaled and systemic. Biol Neonate 1999;76(suppl 1):29-40.

12 Larroque B, Samain H. Groupe Epipage. Epipage study: mortality of very premature infants and state of progress at follow up. J Gynecol Obstet Biol Reprod 2001;30:S33-41.

13 Lee SK, McMillan DD, Ohlsson A, et al. Variations in practice and outcomes in the Canadian NICU Network: 1996-1997. Pediatrics 2000;106:1070-9.

14 Lemons JA, Baver CR, Oh W, et al. Very low birth weight outcomes of the National Institutes of Child Health and Human Development Neonatal Research Network, January 1995 through December 1996. Pediatrics 2001; 107:el.

15 Jobe AH, Ikegami M. Mechanisms initiating lung injury in the preterm. Early Hum Dev 1998;53:81-94.

16 Halliday HL, Ehrenkranz RA. Early postnatal (<96 hours) corticosteroids for preventing chronic lung disease in preterm infants. Cochrane Database Syst $\operatorname{Rev} 2003 ;(1): C D 001146$.

17 Halliday HL, Ehrenkranz RA. Moderately early (7-14 days) postnatal corticosteroids for preventing chronic lung disease in preterm infants. Cochrane Database Syst Rev 2003;(1):CD001144.

18 Halliday HL, Ehrenkranz RA. Delayed (>3 weeks) postnatal corticosteroids for chronic lung disease in preterm infants. Cochrane Database Syst Rev 2003; (1):CD001145

19 Stark AR, Carlo WA, Tyson JE, et al. Adverse effects of early dexamethasone in extremely-low-birth-weight infants. National Institute of Child Health and Human Development Neonatal Research Network. N Engl J Med 2001;344:95-101.

20 Yeh TF, Lin YJ, Huang CC, et al. Early dexamethasone therapy in preterm infants: a follow-up study. Pediatrics 1998;101:e7.

21 Shinwell ES, Karplus M, Reich D, et al. Early postnatal dexamethasone treatment and increased incidence of cerebral palsy. Arch Dis Child Fetal Neonatal Ed 2000;83:F177-81.

22 O'Shea T, Kothadia J, Klinepeter K, et al. Randomized placebo-controlled trial of a 42-day tapering course of dexamethasone to reduce the duration of ventilator dependency in very low birth weight infants: outcome of study participants at 1-year adjusted age. Pediatrics 1999;104:15-21.

23 Baud O. Is perinatal dexamethasone treatment safe in preterm infants? Dev Med Child Neurol 2001;86(suppl):23-5.

24 Barrington KJ. The adverse neuro-developmental effects of postnatal steroids in the preterm infant: a systematic review of RCTs. BMC Pediatr 2001;1:1.

25 Halliday HL. Early postnatal dexamethasone and cerebral palsy. Pediatrics 2002; 109:1168-9.

26 Romagnoli C, Zecca E, Luciano R, et al. A three-year follow up of preterm infants after moderately early treatment with dexamethasone. Arch Dis Child Fetal Neonatal Ed 2002;87:F55-8.

27 Romagnoli C, Zecca E, Luciano R, et al. Controlled trial of early dexamethasone treatment for the prevention of chronic lung disease in preterm infants: a 3-year follow-up. Pediatrics 2002;109:e85.

28 Bos AF, Martiin A, van Asperen RM, et al. Qualitative assessment of general movements in high-risk preterm infants with chronic lung disease requiring dexamethasone therapy. J Pediatr 1998;132:300-6

29 Kuban KC, Leviton A. Cerebral palsy. N Engl J Med 1994;330:188-95.

30 Inder TE, Huppi PS, Warfield S, et al. Periventricular white matter injury in the premature infant is followed by reduced cerebral cortical gray matter volume at term. Ann Neurol 1999;46:755-60.

31 Murphy BP, Inder TE, Huppi PS, et al. Impaired cerebral cortical gray matter growth after treatment with dexamethasone for neonatal chronic lung disease. Pediatrics 2001; 107:217-21.

32 Ajayi-Obe M, Saeed N, Cowan FM, et al. Reduced development of cerebral cortex in extremely preterm infants. Lancet 2000;356:1162-3.

33 Modi N, Lewis $\mathrm{H}, \mathrm{Al}-\mathrm{Naqeeb} \mathrm{N}$, et al. The effects of repeated antenatal glucocorticoid therapy on the developing brain. Pediatr Res 2001;50:581-5. 
34 Howard $\mathrm{H}$. Reductions in size and total DNA of cerebrum and cerebellum in adult mice after corticosterone treatment in infancy. Exp Neurol 1968;22:191-208.

35 Riva MA, Fumagalli F, Racagni G. Opposite regulation of basic fibroblast growth factor and nerve growth factor gene expression in rat cortical astrocytes following dexamethasone administration. J Neurochem 1995;64:2526-33.

36 Goodman CS, Tessier-Lavigne M. Molecular mechanisms in axon guidance and targeted recognition. In: Cowan WM, Jessell TM, Zipursky SL, eds. Molecular and cellular approaches to neural development. New York: Oxford University Press, 1997:108-78.

37 Saliba E, Marret S. Cerebral white matter damage in the preterm infant: pathophysiology and risk factors. Semin Neonatol 2001;6:121-33.

38 Dammann O, Leviton A. Maternal intrauterine infection, cytokines, and brain damage in the preterm newborn. Pediatr Res 1997;42:1-8.

39 Yoon BH, Romero R, Yang SH, et al. Interleukin-6 concentrations in umbilical cord plasma are elevated in neonates with white matter lesions associated with periventricular leukomalacia. Am J Obstet Gynecol 1996;174:1433-40.

40 Nelson KB, Dambrosia JM, Grether JK, et al. Neonatal cytokines and coagulation factors in children with cerebral palsy. Ann Neurol 1998:44:665-75.

41 Volpe JJ. Neurobiology of periventricular leukomalacia in the premature infant. Pediatr Res 2001;50:553-62.

42 Back SA, Han BH, Luo NL, et al. Selective vulnerability of late oligodendrocyte progenitors to hypoxia-ischemia. J Neurosci 2002;22:455-63.

43 Kauffman F, Seidler FJ, Slotkin TA. Prenatal dexamethasone exposure causes loss of neonatal hypoxia tolerance: cellular mechanisms. Pediatr Res 1994:35:515-22.

44 Tombaugh GC, Yang SH, Swanson RA, et al. Glucocorticoids exacerbate hypoxic and hypoglycaemic hippocampal injury in vitro. J Neurochem 1992;59:137-46.

45 Prodanov D, Mantchev G, lliev A, et al. Effects of dexamethasone in rat neonatal model of axotomy-induced motoneuronal cell death. Arch Physiol Biochem 1998; 106:355-61

46 Tsubota S, Adachi N, Chen J, et al. Dexamethasone changes brain monoamine metabolism and aggravates ischemic neuronal damage in rats. Anesthesiology 1999:90:515-23.

47 Tuor UI, Chuman PD, Del Bigio MR. Prevention of hypoxic-ischaemic damage with dexamethasone is dependent on age and not influenced by fasting. Exp Neurol 1995; 132:116-22.

48 Flavin MP. Influence of dexamethasone on neurotoxicity caused by oxygen and glucose deprivation in vitro. Exp Neurol 1996;139:34-8.
49 Arquie $\mathrm{C}$, Leroux $\mathrm{P}$, Bodenant $\mathrm{C}$, et al Glucocorticoid treatment in an ischaemic-like excitotoxic model of periventricular leucomalacia in mice. Br J Obstet Gynaecol 2002;109:989-96.

50 McGowan JE, Sysyn G, Petersson KH, et al. Effect of dexamethasone treatment on maturational changes in the NMDA receptor in sheep brain. J Neurosci 2000;20:7424-9.

51 Tahraoui SL, Marret S, Bodenant C, et al. Central role of microglia in neonatal excitotoxic lesions of the murine periventricular white matter. Brain Pathol $2001 ; 11: 56-71$

52 Marret S, Gressens P, Evrard P. Arrest of neuronal migration by excitatory amino acids in hamster developing brain. Proc Natl Acad Sci USA 1996;93:15463-8

53 Schwab M, Antonow-Schlorke I, Kuhn B, et al. Effect of antenatal betamethasone treatment on microtubule-associated proteins MAP1B and MAP2 in fetal sheep. J Physiol 2001;530:497-506.

54 Weichsel ME. The therapeutic use of glucocorticoid hormones in the perinatal period. Potential neurological hazards. Ann Neurol 1977;46:364-6.

55 Benesova O, Pavlik A. Perinatal treatment with glucocorticoids and the risk of maldevelopment of the brain. Neuropharmacology 1989;28:89-97.

56 Flagel SB, Vazquez DM, Watson SJ Jr, et al. Effects of tapering neonatal dexamethasone on rat growth, neurodevelopment, and stress response. Am J Physiol Regul Integr Comp Physiol 2002;282:R55-63.

57 Stone DJ, Walsh JP, Sebro R, et al. Effects of pre- and postnatal corticosterone exposure on the rat hippocampal GABA system. Hippocampus $2001 ; 11: 492-507$

58 Shi B, Rabin SJ, Brandoli C, et al. Dexamethasone induces hypertrophy of developing medial septum cholinergic neurons: potential role of nerve growth factor. J Neurosci 1998:18:9326-34.

59 Baud O, Foix-L'Helias L, Kaminski M, et al. Antenatal glucocorticoid treatment and cystic periventricular leukomalacia in very premature infants. N Engl J Med 1999;341:1190-6.

60 Baud O, Laudenbach V, Evrard P, et al. Neurotoxic effects of fluorinated glucocorticoid preparations on the developing mouse brain: role of preservatives. Pediatr Res 2001;50:706-11.

61 Watterberg KL, Gerdes JS, Gifford KL, et al. Prophylaxis against early adrenal insufficiency to prevent chronic lung disease in premature infants. Pediatrics 1999:104:1258-63.

62 Andre $\mathrm{P}$, Thebaud B, Odievre MH, et al. Methylprednisolone, an alternative to dexamethasone in very premature infants at risk of chronic lung disease. Intensive Care Med 2000;26:1496-500.

63 Shah SS, Ohlsson A, Halliday H, Shah VS. Inhaled versus systemic corticosteroids for preventing chronic lung disease in ventilated very low birth weight preterm neonates. Cochrane Database Syst Rev 2003;(1):CD002058. 